\title{
Optimal weed population control using nonlinear programming
}

\author{
Elenice W. Stiegelmeier ${ }^{1}$ - Vilma A. Oliveira ${ }^{2}$. \\ Geraldo N. Silva ${ }^{3}$. Décio Karam ${ }^{4}$
}

Received: 10 April 2015 / Revised: 9 September 2015 / Accepted: 28 September 2015 /

Published online: 11 October 2015

(C) SBMAC - Sociedade Brasileira de Matemática Aplicada e Computacional 2015

\begin{abstract}
A dynamic optimization model for weed infestation control using selective herbicide application in a corn crop system is presented. The seed bank density of the weed population and frequency of dominant or recessive alleles are taken as state variables of the growing cycle. The control variable is taken as the dose-response function. The goal is to reduce herbicide usage, maximize profit in a pre-determined period of time and minimize the environmental impacts caused by excessive use of herbicides. The dynamic optimization model takes into account the decreased herbicide efficacy over time due to weed resistance evolution caused by selective pressure. The dynamic optimization problem involves discrete variables modeled as a nonlinear programming (NLP) problem which was solved by an active set algorithm (ASA) for box-constrained optimization. Numerical simulations for a case study illustrate the management of the Bidens subalternans in a corn crop by selecting a sequence of only one type of herbicide. The results on optimal control discussed here will
\end{abstract}

Communicated by Natasa Krejic.

$凶 \quad$ Elenice W. Stiegelmeier elenicew@utfpr.edu.br

Vilma A. Oliveira

vilmao@sc.usp.br

Geraldo N. Silva

gsilva@ibilce.unesp.br

Décio Karam

decio.karam@embrapa.br

1 Department of Mathematics, Universidade Tecnológica Federal do Paraná, Cornélio Procópio, PR 86300-000, Brazil

2 Department of Electrical and Computer Engineering, Universidade de São Paulo, São Carlos, SP 13566-590, Brazil

3 Department of Applied Mathematics, Universidade Estadual Paulista, São José do Rio Preto, SP 15054-000, Brazil

4 Empresa Brasileira de Pesquisa Agropecuária, Sete Lagoas, MG 35701-970, Brazil 
give support to make decision on the herbicide usage in regions where weed resistance was reported by field observations.

Keywords Mathematical modeling · Population dynamics · Nonlinear programming · Weed management

\section{Mathematics Subject Classification 90C30 Nonlinear programming}

\section{Introduction}

Weeds grow naturally in agricultural soils and are highly competitive for resources that are necessary to the crop growth. The competition between weeds and crop plants occurs when two or more plants share the available resources for their growth and development which are limited in a common ecosystem. A plant may inhibit another by limiting its resources consumption. For this reason, the weed control strategies are essential to maximize the productivity of a crop.

The weed management aims to avoid losses due to competition, to benefit crop conditions, to avoid further infestation and to protect the environment. The main method of weed control is the use of herbicide. However, it is of most importance to understand the evolution of resistance in weed population.

The development of resistance to herbicide in agricultural weed population is common and well known. There has been an increasing interest in modeling the resistance evolution in weed populations (Maxwell et al. 1990; Diggle et al. 2003; Gressel 2009; Neve et al. 2011).

Resistance is essentially a natural phenomenon which occurs in weed populations, but it is only noticed when a selection pressure is applied. The repeated application of one or more herbicide modes of action in a weed population selects individuals of species that can survive the herbicide treatment (Powles and Shaner 2001). This phenomenon characterizes a selection pressure, thereby increasing the proportion of resistant individuals in the next generation.

The weed resistance to herbicide occurs on account of an evolutionary process. The development of herbicide-resistant $(\mathrm{R})$ weed biotypes is due to the selection pressure caused by intensive herbicide use. The functions of the gene frequencies of dominant and recessive alleles due to the selective pressure imposed by the herbicide follow the principles of population genetics (Britton 2003).

Optimization strategies are used in several weed management programs (Jones and Cacho 2000; Jones et al. 2006; Kotani et al. 2009, 2011). In these papers, dynamic programming techniques are used to find the optimal strategies. In Jones and Cacho (2000) and Jones et al. (2006), the optimal level of weed control that maximized economic benefits was obtained in terms of a single herbicide dose sequence. The Pontryagin Maximum Principle and dynamic programming were used in solving the considered optimal control problem. Kotani et al. $(2009,2011)$, using a dynamic model of weed management, proposed an optimal decision rule for the removal of weeds, including whether or not to eradicate them.

Optimal control problem is also used in agriculture to control pest population. In Rafikov and Balthazar (2005), an optimal control problem is developed as a management strategy to maintain the density of the pest population in the equilibrium below some economic injury level. In this management strategy, the Pontryagin Maximum Principle was used to drive the pest ecosystem equilibrium to the desired level and dynamic programming to stabilize the ecosystem level. In Christiaans et al. (2007), an optimal pest control is formulated to determine the optimal crop return by applying pesticides and fertilizers in a ecosystem with two species in a predator-prey relationship. 
In modeling the weed population growth under control, an important effect to consider is the resistance to herbicides. In this paper, the Jones and Cacho (2000) weed population model is extended to incorporate the resistance dynamics. In addition, we proposed a weed control strategy aimed at reducing the use of herbicide, maximizing economic returns and minimizing the environmental impacts caused by excessive use of herbicide, using a nonlinear programming (NLP) solved by an active set algorithm (ASA) for box-constrained optimization. The numeric solutions for a sequence of one single herbicide doses considering two herbicides are presented.

\section{Population model considering the weed resistance dynamics}

\subsection{Weed population dynamic model}

The weed dynamics we consider consists of the weed seed bank and seedling densities denoted as $x_{t}$ and $y_{t}$, respectively, which follows closely (Jones and Cacho 2000). Let $t$ denoted the production cycle, the weed population model with the resistance phenomenon in which all the parameters are assumed to be nonnegative, has the following form

$$
\begin{gathered}
y_{t}=x^{g} \delta x_{t}, x_{t_{0}}=x_{0} \\
y_{t}^{a}=\left(1-\rho\left(u_{t}\right)\right) y_{t} \\
x_{t}^{r}=\exp \left[\gamma \ln y_{t}^{a} /\left(\mu+\varepsilon \ln y_{t}^{a}\right)\right] \\
x_{t}^{n}=\kappa x_{t}^{r}-\eta+\xi \\
x_{t+1}=x_{t}^{n}+(1-\Psi)(1-\delta) x_{t},
\end{gathered}
$$

with parameters defined in Table 1.

The structure of the model (1)-(5) is based on the life cycle of weeds in which the initial population $x_{0}$ is the seed bank of viable and non-germinated seeds present in a single agricultural field. In the model, (1) describes the emergence plants from the seed bank, (2) the relative survival of emerged seedlings determined by the weed management strategies employed during each iteration, (3) describes the survived mature plants produced by seeds, (4) describes the proportion of new seeds. Finally, in (5), the newly produced seeds are added to the soil seed bank at the end of the growing season.

The propagation of $x_{t}^{r}$ described by (3) was constrained to zero when $y_{t}^{a}<0.5$ plants per $m^{2}$, due to the nature of the functional form used, as it degenerates to $e^{\frac{\gamma}{\varepsilon}}$ as $y_{t}^{a}$ approaches zero.

Equations (1)-(5) can be condensed by forward substitution ( $y_{t}$ given by (1) into (2), then $y_{t}^{a}$ into (3) and so on), yielding the following equation

$$
x_{t+1}=g\left(x_{t}, u_{t}\right),
$$

where

$$
g\left(x_{t}, u_{t}\right)=(1-\Psi)(1-\delta) x_{t}+\kappa \exp \left(\frac{\gamma \ln \left(\left(1-\rho\left(u_{t}\right)\right) x^{g} \delta x_{t}\right)}{\mu+\varepsilon \ln \left(\left(1-\rho\left(u_{t}\right)\right) x^{g} \delta x_{t}\right)}\right)-\eta+\xi .
$$

The dynamics of weed seed bank is given in (6), in which $\rho$ describe the herbicide-induced mortality of seedlings in cycle $t$ where the control variable is described by $u_{t}$ and determined by the weed management strategy employed during each iteration. 
Table 1 Population dynamic model variables and parameters

\begin{tabular}{ll}
\hline$x_{t}$ & Weed seed bank density in cycle $t\left(\mathrm{~m}^{-2}\right)$ \\
$y_{t}$ & Seedlings in cycle $t\left(\mathrm{~m}^{-2}\right)$ \\
$y_{t}^{a}$ & Density of mature plants $\left(\mathrm{m}^{-2}\right)$ \\
$x_{t}^{r}$ & Seeds resulting from the reproduction of weeds $\left(\mathrm{m}^{-2}\right)$ \\
$x_{t}^{n}$ & New seeds added to the seed bank in cycle $t\left(\mathrm{~m}^{-2}\right)$ \\
$x^{g}$ & Proportion of germination \\
$\delta$ & Annual germination rate of weed seeds \\
$u_{t}$ & Dose of herbicide in cycle $t\left(\mathrm{~L} \mathrm{ha}^{-1}\right)$ \\
$\rho$ & The herbicide-induced mortality of seedlings \\
$\gamma, \mu, \varepsilon$ & Regression coefficients (Medd et al. 1995) \\
$\kappa$ & Survival rate of new seeds \\
$\eta$ & Seed export such as removal of seeds at harvest $\left(\mathrm{m}^{-2}\right)$ \\
$\xi$ & Import of seeds (m $\left.{ }^{-2}\right)$ \\
$\Psi$ & Death rate of dormant seeds \\
\hline
\end{tabular}

\subsection{Dose-response model}

The relationship between herbicide doses and plant response is of fundamental importance to understand herbicide efficacy and mode of action. The dose-response is usually analyzed using a log-logistic curve (Christensen et al. 1990; Streibig and Kudsk 1993; Seefeldt et al. 1995 ) and is used to quantify plant sensitivity to a herbicide (Karam et al. 2004; Dan et al. 2010). Resistant plants have a lower sensitivity to herbicide and their dose-response function differ from the dose-response function of susceptible plants. This difference is used to detect cases of resistance to a herbicide (Moss 1999).

A logistic model to be fitted to the survival data is as follows:

$$
\rho(u)=c+\frac{d-c}{1+\exp \left[b\left(\ln (u)-\ln \left(G R_{50}\right)\right)\right]},
$$

where $\rho$ is the induced mortality, $c$ is the lower asymptotic values of $\rho$ and $d$ is the upper asymptotic values of $\rho$, the parameter $\mathrm{GR}_{50}$ is the herbicide rate which produces a survivallevel halfway between the lower limit zero and upper limit $d, u$ is the herbicide dose and the parameter $b$ denotes the relative slope around $\mathrm{GR}_{50}$ (Seefeldt et al. 1995). The fitted logistics model was used to estimate the rate of herbicide that causes $50 \%$ grow reduction $\left(\mathrm{GR}_{50}\right)$. The parameters $b, c, d$ and $G R_{50}$ can be determined experimentally.

One of the advantages of using the curve described by (7) is that the parameters are biologically meaningful. The upper limit $d$ corresponds to the mean response of the control and the lower limit $c$ is the mean response at very high doses. The dose-response (7) is supposed to determine the reduction in mortality of weeds if an herbicide is applied. Then, if the herbicide is not applied it is equal to zero, in others words, $\lim _{u \rightarrow 0} \rho(u)=c=0$.

We formulated a model for the resistance dynamics based on the detection of resistant biotypes to a herbicide via the dose responses. We make the following assumptions: (1) the parameters $c$ and $d$ in both resistant (R) and susceptible (S) biotype dose-response curves are close, (2) the slope $b$ is parallel for different $G R_{50}$ under the same resistant mechanism (Tind et al. 2009; Christoffoleti 2002), (3) the parameter $G R_{50}$ varies according to the proportion 
of $\mathrm{R}$ and $\mathrm{S}$ biotypes, and it is commonly used to estimate the herbicide efficacy (Tind et al. 2009; Powles and Preston 2011).

The adopted dose-response function is thus given by

$$
\rho\left(u_{t}\right)=c_{S}+\frac{d_{S}-c_{S}}{1+\exp \left[b_{R}\left(\ln \left(u_{t}\right)-\ln \left(G R_{50 t}\right)\right)\right]},
$$

where $c_{S}$ indicates the minimum mortality and is taken from the $\mathrm{S}$ biotype dose-response curve, $d_{S}$ indicates the maximum mortality (Christoffoleti 2008) and is taken from the $S$ biotype dose-response curve to reflect the maximum mortality, $b_{R}$ is taken from the resistant biotype dose-response curve around the parameter $\mathrm{GR}_{50 t}$ which is modeled as a function of $\mathrm{R}$ and $\mathrm{S}$ biotypes, because in this population both biotypes are present.

In this paper, we assume that the weed management strategy depends on different mortality responses from resistant and susceptible seedlings. Then, we used proportions of both seedlings present in the weed population described as a convex relationship as follows:

$$
\operatorname{GR}_{50 t}\left(R_{t}\right)=R_{t} \mathrm{GR}_{50 R}+\left(1-R_{t}\right) \mathrm{GR}_{50 S},
$$

where $\mathrm{GR}_{50 R}$ and $\mathrm{GR}_{50 S}$ are the doses necessary to reduce to $50 \%$ the resistant and susceptible biotype dose-responses, respectively, and $R_{t}$ is the resistance to herbicides in cycle $t$ obtained as a function of the allele frequency given by the Fisher-Haldane-Wright (FHW) equation which describes the population genetics (Britton 2003). Therefore, model (9) captures informations about both populations $R$ and $S$, present in the seed bank in cycle $t$.

The dose-response function is then dependent not only on the herbicide dose $u_{t}$ but also on the resistance $R_{t}$. This has effect on the modeling of the seed bank, which will be described in Sect. 3.2.

\subsection{Weed resistance dynamic model}

For most weeds, the behavior predicted by the FHW equation (Britton 2003) efficiently represents species with rapid breeding, sexually generating seed through pollen, very different generations from each other, isolated populations and greater interaction within the same population. Therefore, the FHW equation is used to describe the genetic evolution of the weed resistance.

\subsubsection{Selection pressure for the dominant and recessive allele frequencies}

The function of genetic frequencies of dominant and recessive alleles under selective pressure is described next (Britton 2003). Let the allele frequencies at the end of the gametic phase of generation $t$ be $p_{t}$ and $q_{t}$. Let the ratio $w_{\mathrm{AA}}: w_{\mathrm{Aa}}: w_{\mathrm{aa}}$ define the probability of survival from zygotic phase to breeding phase for the various genotypes. According to Britton (2003), $w_{\text {aa }}$ is usually assumed to be equal to 1 , such that $w_{\mathrm{AA}}$ and $w_{\mathrm{Aa}}$ are the relative selective values of genotypes $\mathbf{A A}$ and Aa. With $p_{t}^{2}, 2 p_{t} q_{t}$ and $q_{t}^{2}$ genotype frequencies, at the beginning of the zygotic phase the ratios of the genotypes $\mathbf{A A}, \mathbf{A a}$ and aa at the breeding phase were modified to

$$
w_{\mathrm{AA}} p_{t}^{2}: 2 w_{\mathrm{Aa}} p_{t} q_{t}: w_{\mathrm{aa}} q_{t}^{2}
$$

and the alleles $\mathbf{A}$ and $\mathbf{a}$ frequencies are now in the ratio

$$
w_{\mathrm{AA}} p_{t}^{2}+w_{\mathrm{Aa}} p_{t} q_{t}: w_{\mathrm{Aa}} p_{t} q_{t}+w_{\mathrm{aa}} q_{t}^{2} .
$$


Finally, the change in allele $\mathbf{A}$ frequency at the end of the gametic phase may be described by

$$
p_{t+1}=\frac{w_{\mathrm{AA}} p_{t}^{2}+w_{\mathrm{Aa}} p_{t} q_{t}}{w_{\mathrm{AA}} p_{t}^{2}+2 w_{\mathrm{Aa}} p_{t} q_{t}+w_{\mathrm{aa}} q_{t}^{2}},
$$

which can be written in the recursive form as

$$
p_{t+1}=p_{t}+\sigma\left(p_{t}\right)
$$

where

$$
\sigma\left(p_{t}\right)=p_{t} q_{t} \frac{\left(w_{\mathrm{AA}}-w_{\mathrm{Aa}}\right) p_{t}+\left(w_{\mathrm{Aa}}-w_{\mathrm{aa}}\right) q_{t}}{w_{\mathrm{AA}} p_{t}^{2}+2 w_{\mathrm{Aa}} p_{t} q_{t}+w_{\mathrm{aa}} q_{t}^{2}} .
$$

This is the FHW introduced earlier which describes the change in gene frequencies at period $t+1$.

We represent the weed seed bank as genetic material that participates in the selection process. In this process, the dormancy seeds do not undergo selective pressure, but the adult plants do. Finally, eliminating dead and germinated seeds from the existing bank and adding the new seeds into it, we obtain

$$
p_{t+1}=p_{t}+\chi_{t} \sigma\left(p_{t}\right)
$$

with $\chi_{t}<1$, and

$$
\chi_{t}=\frac{x_{t}^{n}}{x_{t}}
$$

Equation (14) can be written as

$$
p_{t+1}=v\left(x_{t}, p_{t}, u_{t}\right)
$$

where

$$
v\left(x_{t}, p_{t}, u_{t}\right)=p_{t}+\chi_{t} \sigma\left(p_{t}\right) .
$$

The dynamic of seed bank, represented by $\chi_{t}$, considers the proportion of new seeds to be added in the seed bank in the next generation. This factor is important because of the allele frequencies' change in each generation thus it is necessary to represent more accurately the allele frequencies of the seed bank.

The ratio of the evolution advantages relative to the selection in (14) is given by

$$
\left[\begin{array}{lll}
w_{\mathrm{AA}} & w_{\mathrm{Aa}} & w_{\mathrm{aa}}
\end{array}\right]^{T}=E s+\left[\begin{array}{lll}
1 & 1 & 1
\end{array}\right]^{T},
$$

where $s$ is the coefficient of strength of selection for dominant and recessive alleles and $E$ is a vector that defines the relative selective values of genotypes AA and Aa given by:

$$
E=\left\{\begin{array}{lll}
{\left[\begin{array}{lll}
1 & 1 & 0
\end{array}\right]^{T},} & \text { if dominant } \\
{\left[\begin{array}{lll}
1 & 0 & 0
\end{array}\right]^{T},} & \text { if recessive }
\end{array}\right.
$$

\subsubsection{Resistant genotype}

The initial population is the viable seed bank, non-germinated seeds found in agricultural fields. Within this seed bank, S and R individuals exist in numbers determined by the initial frequency of resistant alleles. 
The percentage of resistant genotype $R_{t}$ can be introduced by knowing the plant phenotype. The proportion of new seeds of each genotype ( $\mathbf{A A}, \mathbf{A a}, \mathbf{a a})$ is determined by the population genetics.

The cases of dominant and recessive alleles are studied. In the case of the resistance being connected to recessive alleles, the homozygous aa $\left(\left(1-p_{t}\right)^{2}\right)$ is responsible for the trait. In the case of dominant alleles, the homozygous $\mathbf{A A}\left(p_{t}^{2}\right)$ and the heterozygous $\mathbf{A a}\left(2 p_{t}\left(1-p_{t}\right)\right)$ are responsible for the resistance.

The model for the resistant genotype follows the Hardy-Weinberg equilibrium and is formulated as

$$
R_{t}= \begin{cases}p_{t}^{2}+2 p_{t}\left(1-p_{t}\right), & \text { if dominant } \\ \left(1-p_{t}\right)^{2}, & \text { if recessive }\end{cases}
$$

Therefore, the resistance dynamic model for selective pressure taken into account the seed bank is given by (14)-(18).

\subsection{Multiple resistance dynamic model}

The most intractable problems of herbicide resistance involve weeds which exhibit multiple herbicide resistance. The phenomenon of multiple herbicide resistance can be seen as the expression of different herbicide modes of action. Multiple herbicide-resistant weeds may possess from two to various distinct resistance mechanisms and may exhibit resistance to different herbicide (Powles and Preston 2011). The weeds with multiple herbicide resistance have a speed up evolution of resistance dynamics to the herbicide, where each herbicide shows a different selection pressure.

In Maxwell et al. (1990), Diggle et al. (2003) and Gressel and Segel (1978), the segregation of the allele frequencies was considered to use different herbicide modes of action to control the weed infestation. We do not consider the segregation of the allele frequencies in the weed population model.

The weed population and resistance dynamics are thus described by (1)-(9) and (14)-(18). The dose-response parameters are defined according to the selected herbicide.

\section{Weed management optimization problem}

Differing from Jones and Cacho (2000), we propose a dynamic optimization model for weed control considering the resistance evolution to a certain herbicide.

\subsection{Defining the economic model}

The economic problem faced by decision maker is to determine the levels of input of all production factors, including weed control, which maximize net returns and minimize environmental impacts. The crop yield denoted $Y$, which is a function of the weed density, the weed resistance and the weed control, is represented in the form of

$$
Y=h\left(x_{t}, p_{t}, u_{t}\right) .
$$

This function can be separated in equations for the weed-free yield denoted $Y_{0}$, the yield loss associated with the weed density, the weed allele frequencies and the weed control denoted $Y_{L}$ and the yield loss associated to phytotoxic effects of herbicide denoted $Y_{p}$. The crop yield is thus obtained as 


$$
Y=Y_{0}\left(1-Y_{L}\right)\left(1-Y_{p}\right)
$$

Cousens (1985) argued that the appropriate loss function that describes yield loss as a function of weed density is a rectangular hyperbola function

$$
Y_{L}=\frac{a D}{1+\frac{a}{m} D},
$$

where $a$ is the percentage of yield loss per unit weed density $\left(m^{-2}\right), m$ an estimate of the maximum yield loss of a weed crop relative to the yield of a weed-free crop and $D$ a function of weed density which estimates the efficiency of the herbicide dose $\rho\left(u_{t}, R_{t}\right)$

$$
D=y_{t}\left(1-\rho\left(u_{t}, R_{t}\right)\right), \quad 0 \leq \rho \leq 1,
$$

with $\rho\left(u_{t}, R_{t}\right)$ given by (8).

The yield loss associated to phytotoxic effects of herbicide was estimated as Pandey and Medd (1990)

$$
Y_{p}=\varphi u_{t}
$$

where $\varphi$ is an adjusted parameter that depends on the applied herbicide.

The economic model maximizes net returns and minimizes the weed resistance, for a initial level of weed infestation. Thus, the profit function denoted $\pi$ is defined as:

$$
\pi\left(x_{t}, p_{t}, u_{t}\right)=P_{y} Y\left(x_{t}, p_{t}, u_{t}\right)-P_{u} u_{t}-C,
$$

where $P_{y}$ is the crop price, $P_{u}$ is the per unit cost of weed control, $C$ is the constant application cost for the weed control input (machinery and labor) and cost of the production of the remaining production factors. The profit function (22) is determined not only by the control variable but also by the weed density $x_{t}$ and weed resistance $p_{t}$.

\subsection{Optimization model}

Let $u$ be the applied herbicide dose. Using (5) and (14), the dynamic model for the seed bank density and allele frequencies for applied herbicide is written in terms of functions $g$ and $v$, respectively, as

$$
\begin{aligned}
& g\left(x_{t}, p_{t}, u_{t}\right)=x_{t+1} \\
& v\left(x_{t}, p_{t}, u_{t}\right)=p_{t+1},
\end{aligned}
$$

where $g$ represents the change in the seed bank and $v$ the change in the allele frequencies in time $t$.

The vector field, which represents the speed of the dynamics evolution, is chosen as $[g v]^{T}$, where the first element represents the evolution of the seed bank density and the second the allele frequencies for applied herbicide.

We point out that due to (6) and (15) the vector field is dependent on both state variables $x_{t}$ and $p_{t}$ as opposed to previous models where either the seed bank density or the allele frequency in populations were considered separately. Here we model the behavior of the seed bank density as well as the allele frequency in the seed population and therefore interactions between the equations in the system modeling are expected to happen. The proposed model captures these interactions through the dose-response and resistance functions analysis. 
The optimization model that considers a single herbicide application strategy is modeled as a NLP problem. The variables are the seed bank $x_{t}$, the allele frequencies $p_{t}$, the herbicide dose $u_{t}$ which should be applied at each time. Then, the NLP problem is formulated as

$$
\begin{gathered}
\max _{u_{t}} J(x, p)=\sum_{t=0}^{T} \alpha^{t} \pi\left(x_{t}, p_{t}, u_{t}\right) \\
\text { subject to } \\
x_{t+1}=g\left(x_{t}, p_{t}, u_{t}\right), \quad x(0)=x_{0} \\
p_{t+1}=v\left(x_{t}, p_{t}, u_{t}\right), \quad p(0)=p_{0} \\
0 \leq u(t) \leq u_{\max } \\
x_{t}, p_{t}, u_{t} \in \mathbb{R}
\end{gathered}
$$

where $J$ is the objective function, $\pi$ the smooth function (22), $T$ is the planning horizon, $\alpha^{t} \in(0,1)$ the discount rate (Kennedy 1986) and $u_{\max }$ the highest dose of herbicide allowed in the field. The objective function $J$ is a smooth nonlinear and generally concave function. The state variables are $x_{t}$ and $p_{t}$ and $u_{t}$ represents the control variable.

The optimal control theory can be used to determine the annual rate of herbicide that maximizes the objective functional. An important role in this problem are the costate variables, denoted by $\lambda_{t}$ e $\beta_{t}$, which are similar to the Lagrange multipliers. The costate variables are inserted in the optimal control problem through the Hamiltonian function. Following Kennedy (1986), the Hamiltonian function for the weed management problem is established as follows:

$$
\begin{aligned}
H_{t}\left(\lambda_{t+1}, \beta_{t+1}, x_{t}, p_{t}, u_{t}\right)= & \pi\left(x_{t}, p_{t}, u_{t}\right)+\alpha \lambda_{t+1} g\left(x_{t}, p_{t}, u_{t}\right) \\
& +\alpha \beta_{t+1} v\left(x_{t}, p_{t}, u_{t}\right) .
\end{aligned}
$$

The Hamiltonian function $H_{t}$ is the net profit obtained from an existing level of the state variables, $x_{t}$ and $p_{t}$ and control $u_{t}$ plus the value of any change in the stock of the state variables valued at the costate variables $\lambda_{t+1}$ e $\beta_{t+1}$. When $g_{t}$ is multiplied by $\lambda_{t+1}$, this result is converted to a monetary value and represents the rate of change of the economic value of the seed bank corresponding to herbicide dose applied, the same occurs when $v_{t}$ is multiplied by $\beta_{t+1}$. In general, this value can be viewed as the future profit effect of weed population change (Jones and Cacho 2000).

According to Kennedy (1986), the first-order conditions for a resource management problem, given by the Maximum Principle of Pontryagin, are

$$
\begin{aligned}
\frac{\partial H_{t}}{\partial u_{t}} & =P_{y} \frac{\partial Y}{\partial u_{t}}-P_{u}+\alpha \lambda_{t+1} \frac{\partial g}{\partial u_{t}}+\alpha \beta_{t+1} \frac{\partial v}{\partial u_{t}}=0 \\
\alpha \lambda_{t+1} & =-\frac{\partial H_{t}}{\partial x_{t}}=-P_{y} \frac{\partial Y}{\partial x_{t}}-\alpha \lambda_{t+1} \frac{\partial g}{\partial x_{t}} \\
x_{t+1} & =\frac{\partial H_{t}}{\partial \lambda_{t+1}}=g\left(x_{t}, p_{t}, u_{t}\right) \\
\alpha \beta_{t+1} & =-\frac{\partial H_{t}}{\partial p_{t}}=-P_{y} \frac{\partial Y}{\partial p_{t}}-\alpha \beta_{t+1} \frac{\partial v}{\partial p_{t}} \\
p_{t+1} & =\frac{\partial H_{t}}{\partial \beta_{t+1}}=v\left(x_{t}, p_{t}, u_{t}\right),
\end{aligned}
$$


where (30) is the maximum principle, the standard conditions for maximization with respect to $u_{t},(31)$ and (33) correspond to the costate equation and (32) and (34) are a re-statement of the equation of motion relative to the seed bank and the allele frequency, respectively. The set of equation (30)-(34) allows the solution of the unknown optimal trajectories, that are state variables $x^{*}$ and $p^{*}$, control $u^{*}$ and costate $\lambda^{*}$ and $\beta^{*}$ variables. The state variables depend on the initial state of the system $x_{0}$ and $p_{0}$. Although $x_{0}$ and $p_{0}$ are given, $\lambda_{1}$ and $\beta_{1}$ are unknown and an additional condition, known as the transversality condition, is required to obtain a unique solution. In this problem, where the final time $T$ is given, and the final state $x_{T}$ is free, the transversality condition is $\lambda_{T+1}=0$ e $\beta_{T+1}=1$.

To solve the NLP given by (25)-(28), we use an algorithm proposed by Hager (2006) called active set algorithm (ASA). This algorithm is described in Sect. 4 next.

\section{Solution of the nonlinear programming problem}

The nonlinear programming problem considered is a mathematical programming problem with discrete variables, nonlinear constraints and a nonlinear objective function.

This paper is concerned with a nonlinear programming problem based in box-constrained optimization problem given by (25)-(28), where (25) is the objective functional with $J$ a real-valued, continuously differentiable function defined on the set (28).

To solve the NLP problem, the active set algorithm (ASA) is used (Hager 2006). We consider that the box (28) is replaced by a nonempty, closed and concave set. The solution of the corresponding problem yields the optimal control strategy.

\subsection{Active set algorithm}

We implemented the box-constrained optimization problem using an nonlinear programming problem (NLP) strategy to solve the weed control problem. In the NLP strategy, the decision variable is $u_{t}$ and the state space equation has $u_{t}$ as inputs. Thus, the NLP method is used to obtain an optimal control $u_{t}^{*}$.

The optimization problem (25)-(28) has a box constrained for the control variables, thus it is then necessary to use a box-constrained method. Therefore, the ASA method proposed by Hager (2006) available at Hager (2009) is used. This algorithm consists of a non-monotone gradient projection step, an unconstrained optimization step and a set of rules for branching between the two steps.

The ASA method global convergence to a stationary point is established in Hager (2006). Hager (2006) also showed that the ASA method is superior to the L-BFGS-B (Byrd et al. 1995), the SPG2 v. 2.1 (Birgin et al. 2000), the GENCAN (Birgin and Martínez 2002) and the TRON v. 1.2 (Lin and Moré 1999) methods in terms of CPU time.

Algorithm 1 describes the problem to solve the weed control problem using the ASA method. We emphasize that Algorithm 1 is applied to the general box constraint problem with both upper and lower bounds. To implement the problem, it is necessary to choose the input parameters of the weed control problem.

The functional objective (25), the state functions (26)-(27), the Jacobian of $f=\left[\begin{array}{ll}g & v\end{array}\right]^{T}$ and the box-constrained (28) are given as input of the Algorithm 1. The problem outputs are the optimal control $u_{t}^{*}$ and its corresponding optimal states $x_{t}^{*}$ and $p_{t}^{*}$. In Algorithm 1, the stopping condition used in ASA algorithm was $d_{k}=P\left(u_{k}-G_{k}\right)-u_{k}$, where $P$ denotes the gradient projection onto the domain of $f$ and $G_{k}=\nabla f\left(u_{k}\right)$ the gradient at the iterate $u_{k}$ from ASA. For more details see Hager (2006). 


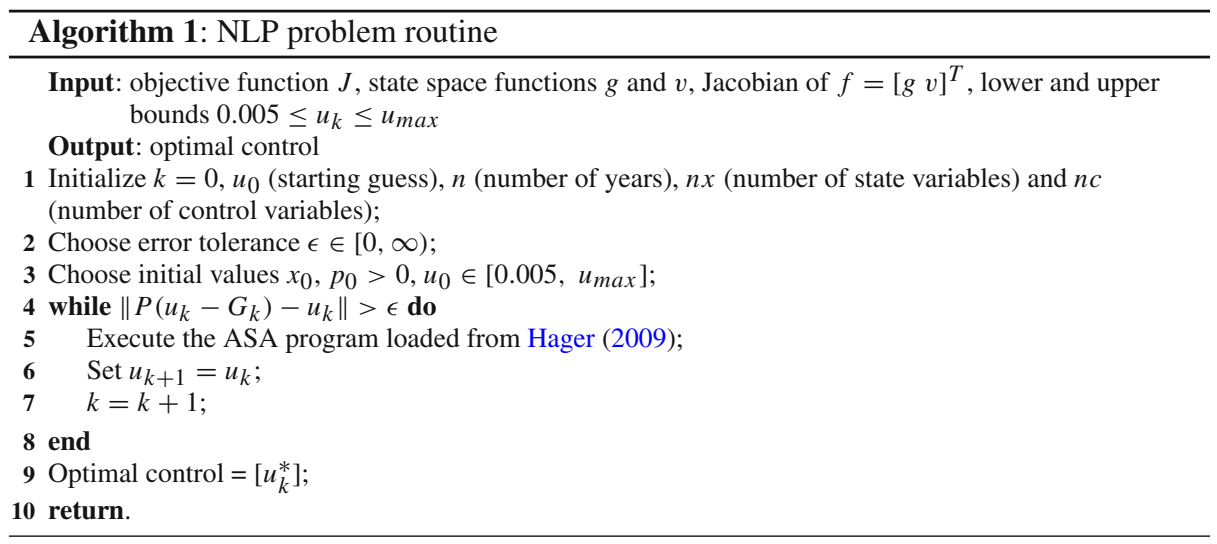

\section{Results}

A case study with the Bidens subalternans in a corn crop by applying two herbicides is presented. The Bidens subalternans is a highly competitive weed, with great adaptability on farm soils, which is due to its high seed production combined with dormancy mechanisms.

The Bidens subalternans has dominant allele with nuclear resistance (Tranel and Wright 2002). This species shows multiple resistance to the acetolactate synthase (ALS) and the photosystem two (PS2) inhibitors (Gazziero et al. 2008; Karam 2011; Heap 2011).

The effective use of herbicide in weed management depends on the knowledge of the characteristics of the herbicide active ingredient. The atrazine herbicide is a well-known herbicide in the class of triazine and it can be applied for pre-emergent (root-absorbed) and post-emergent (foliage-absorbed) control of weed. Its mechanism of action is by inhibition of PS2, causing a series of irreversible damage to plant cells and can be classified as a nonsystemic herbicide (Carvalho et al. 2010). Due to its large use around the world and low soil absortion, the herbicide atrazine is more harmful to the environment (Ralebitso 2002). The nicosulfuron is a systemic, post-emergent (foliage-absorbed) herbicide and working in ALS inhibitors in weeds (Anderson et al. 1998). The nicosulfuron herbicide is widely used in corn crop to weed control, with negative effects on the environment (Oliveira et al. 2009). Therefore, the effective weed control can be accomplished by combining the characteristics of individual herbicides when integrated with weed biological information.

As the model output was particularly sensitive to the initial seed bank density (B. Subalternans population size) and initial frequency of $\mathrm{R}$ alleles, we defined a scenario for simulation. The scenario considered an initial seed bank of 500 (seeds $\mathrm{m}^{-2}$ ) and an initial allele frequency of 0.1 following the characteristics of the area where the seeds were collected. In the simulation, two herbicides (nicosulfuron and atrazine) were considered for post-emergent (foliage-absorbed) control of the weed population. The weed control problem was simulated over a 10 years period.

The parameter values of the dose-response model, $\rho$, were obtained by curve fitting from experimental data of herbicide-induced mortality using the R Statistical Software. The data were collected in a controlled environment setup conducted in Embrapa Milho e Sorgo (see Table 2). The dose-response curves are shown in Fig. 1. The parameter values of the adopted dose-response model (8) used are presented in Table 3. 
Table 2 Dose-response model parameter values for nicosulfuron and atrazine from experimental data

\begin{tabular}{llllrr}
\hline Herbicide & Biotype & $b$ & $c$ & $d$ & GR $_{50}$ \\
\hline Nicosulfuron & Susceptible & -0.80721 & -3.06521 & 102.65965 & 8.57764 \\
& Resistant & -1.28707 & -0.30570 & 34.41258 & 36.12024 \\
Atrazine & Susceptible & -1.38747 & -1.30678 & 105.86746 & 783.09583 \\
& Resistant & -0.68405 & 0.12445 & 212.9900 & 57375.0
\end{tabular}

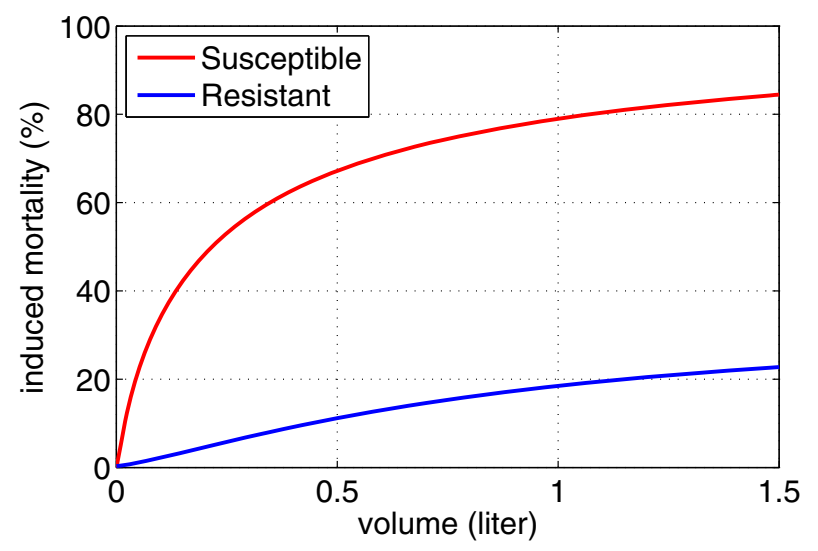

(a)

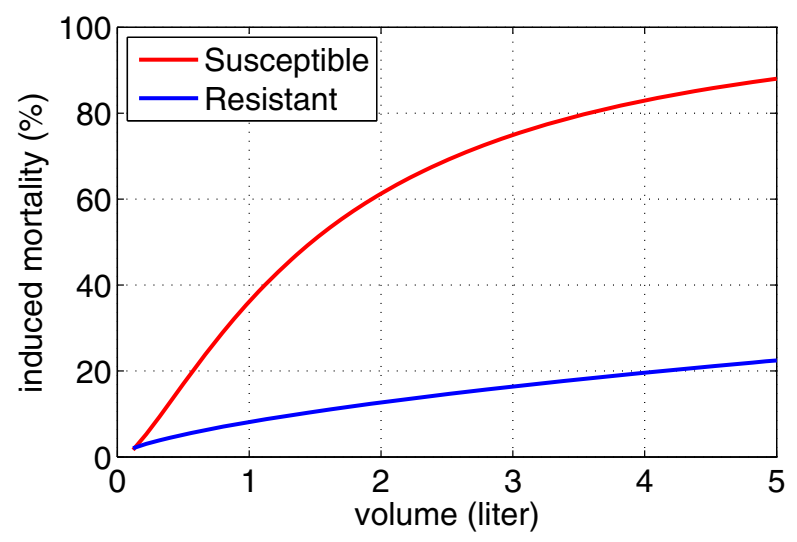

(b)

Fig. 1 Herbicide-induced mortality for resistant and susceptible seedlings for a nicosulfuron and $\mathbf{b}$ atrazine herbicides

The parameter values of the population and economic models used in the annual corn harvest system 2013/2014 (IMEA 2014) are reported in Table 4.

We used the bound-constraints maximization solver ASA to solve the NLP problem. The code was written in C programming language. All experiments were run on a $2.27 \mathrm{GHz}$ Intel core 15 processor $3 \mathrm{~Gb}$ of RAM memory and Windows 7 operating system. The NLP algorithm for the weed problem runs relatively fast, and the average processing time is around $2 \mathrm{~s}$. 
Table 3 Dose-response model parameter values for nicosulfuron and atrazine used in weed resistance model proposed

\begin{tabular}{llllrr}
\hline Herbicide & $b_{R}$ & $c_{S}$ & $d_{S}$ & $\mathrm{GR}_{50 S}$ & $\mathrm{GR}_{50 R}$ \\
\hline Nicosulfuron & -1.28707 & -3.065216 & 102.65965 & 8.577645 & 36.12024 \\
Atrazine & -0.68405 & -1.30678 & 105.86746 & 783.09583 & 57375.00 \\
\hline
\end{tabular}

Table 4 Parameter values used in the numeric simulation $(1=$ nicosulfuron and $2=$ atrazine)

\begin{tabular}{ll}
\hline Population parameters & Value \\
\hline$\delta(\%)$ & 60.00 \\
$\psi(\%)$ & 30.00 \\
$\eta\left(\mathrm{m}^{-2}\right)$ & 0.00 \\
$\xi\left(\mathrm{m}^{-2}\right)$ & 0.00 \\
$\kappa(\%)$ & 35.00 \\
$x^{g}(\%)$ & 80.00 \\
$\gamma$ & 6.80 \\
$\mu$ & 2.00 \\
$\varepsilon$ & 0.67 \\
Economic parameters & \\
$P_{y}\left(\mathrm{R} \$\right.$ ton $\left.^{-1}\right)$ & 534.40 \\
$Y_{0}\left(\right.$ ton ha $\left.^{-1}\right)$ & 8.64 \\
$C\left(\mathrm{R} \$\right.$ ha $\left.^{-1}\right)$ & 954.73 \\
$P_{u}^{1}\left(\mathrm{R} \$ \mathrm{~L}^{-1}\right)$ & 42.90 \\
$P_{u}^{2}\left(\mathrm{R} \$ \mathrm{~L}^{-1}\right)$ & 12.40 \\
$u_{\text {max }}^{1}\left(\mathrm{~L} \mathrm{ha}^{-1}\right)$ & 1.50 \\
$u_{\text {max }}^{2}\left(\mathrm{~L} \mathrm{ha}^{-1}\right)$ & 5.00 \\
$\alpha$ & 0.90 \\
$\varphi^{1}$ & $8.90 \times 10^{-3}$ \\
$\varphi^{2}$ & $2.70 \times 10^{-3}$ \\
$a$ & $1.58 \times 10^{-2}$ \\
$m$ & $4.83 \times 10^{-1}$ \\
\hline &
\end{tabular}

\subsection{Weed population equilibrium}

Consider the dynamic model involving both the seed bank density and the allele frequency which describes the herbicide resistance, (5) and (14), respectively. Fixing the dose $u_{t}$ and initial conditions, the equilibrium points for this system are the fixed points $\left(x^{*}, p^{*}\right)$ such that $\left(x_{t}, p_{t}\right)=\left(g\left(x_{t}, p_{t}, u_{t}\right), v\left(x_{t}, p_{t}, u_{t}\right)\right)$. In other words, the fixed points satisfy

$$
\begin{aligned}
& x_{t+1}=x_{t} \\
& p_{t+1}=p_{t} .
\end{aligned}
$$

In (3), when $y_{t}^{a}<0.5$ plants per $m^{2}$, we set $x_{t}^{r}=0$. Thus, for $\eta=0$ and $\xi=0$ the population model becomes the linear model: 


$$
\begin{aligned}
x_{t+1} & =(1-\Psi)(1-\delta) x_{t} \\
p_{t+1} & =p_{t} .
\end{aligned}
$$

As the eigenvalues are $\lambda_{1}=(1-\Psi)(1-\delta)<1$ and $\lambda_{2}=1$, the linear model (37) is marginally stable. Table 5 shows the equilibrium points for a fixed dose of nicosulfuron and atrazine. The phase plane of the model is shown in Fig. 2.

Table 5 Dynamic model equilibrium points for nicosulfuron and atrazine

\begin{tabular}{lllll}
\hline Herbicide & Dose $\left(\mathrm{L} \mathrm{ha}^{-1}\right)$ & $P_{1}$ & $P_{2}$ & $P_{3}$ \\
\hline Nicosulfuron & 0.107 & $\left(0, p_{0}\right)$ & $(10,1)$ & $(245,1)$ \\
Atrazine & 4.500 & $\left(0, p_{0}\right)$ & $(17,1)$ & $(227,1)$
\end{tabular}

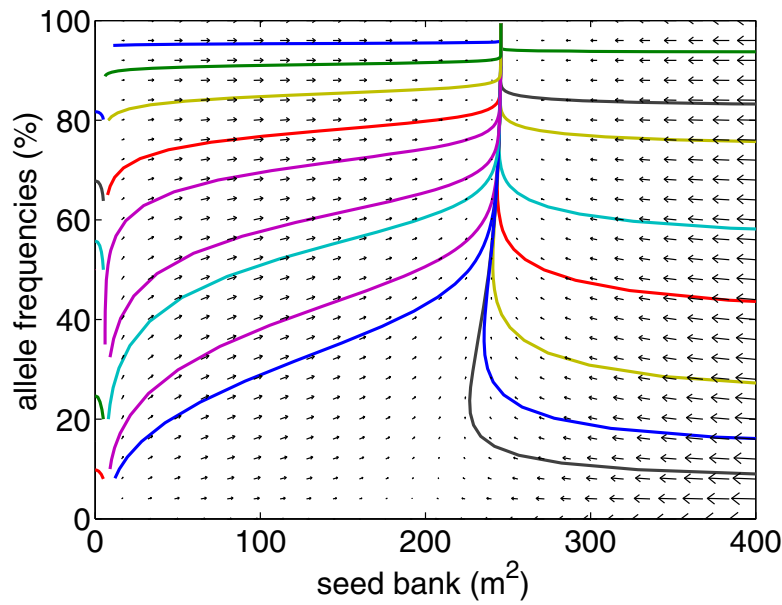

(a)

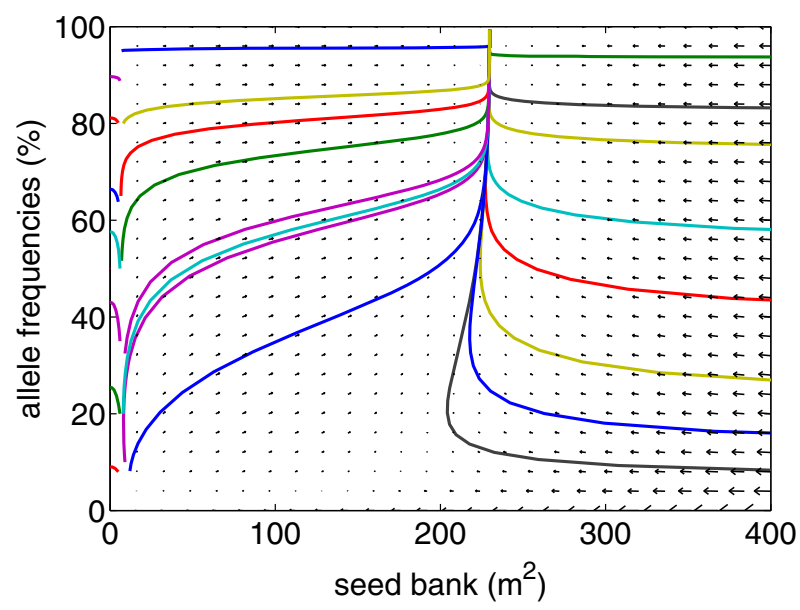

(b)

Fig. 2 Phase plane for fixed dose a nicosulfuron; $\mathbf{b}$ atrazine with selective pressure $s=0.3$

国 Springer $\mathscr{L} \mathfrak{M} M \mathbb{A C}$ 
In the particular context of nonlinear system analysis, a phase plane is a visual display of the behavior of the model variables as it shows the solutions of the dynamic model and their behavior in the neighborhood of each equilibrium point can be qualitatively determined. The phase plane showed in Fig. 2 depicts the solution of the seeds density versus the allele frequency in the time (years) considering different initial conditions denoted as $\left(x_{0}, p_{0}\right)$. In each simulation was used 1000 cycles for both nicosulfuron and atrazine herbicides. In this figure, we observed that exists three equilibrium solutions, as shown in Table 5.

For the nonlinear model described here, $P_{2}$ is an unstable equilibrium solution as the solutions starting near the equilibrium point or equilibrium solution move away from the equilibrium solution. Similarly, $P_{3}$ is a stable equilibrium solution as the solutions starting near the equilibrium all converge to the equilibrium $P_{3}$ as time increases. Finally, for small seed density, the solutions are solutions of the linear model and approach $P_{1}$ given by $x=0$ and $p_{0}$ which is thus said to be a marginally stable equilibrium point.

The phase plane is useful to define the correct weed management strategy in terms of the herbicide doses to be applied. Moreover, the phase plane indicates that the allele frequencies do not decrease even if the weed population reaches low levels, in other words, the allele frequencies have kept an existing trait.

\subsection{Genetic frequencies}

The genetic frequency using the FHW (13) are compared to the FHW (14) model using the seed bank (5) with (8)-(9) and (18). Figure 3 illustrates the dynamics of the allele frequency to (13) model and (14) model using the seed bank with nicosulfuron applied and weak selection for a dominant allele. The dynamics of the allele frequency is similar in both models which means that the weed population model proposed follows the population genetic principles.

\subsection{Optimal control strategy}

We evaluated the dynamics of the seed bank and the resistance evolution. The net average from the NLP problem for two herbicides in an annual application bases is compared to the

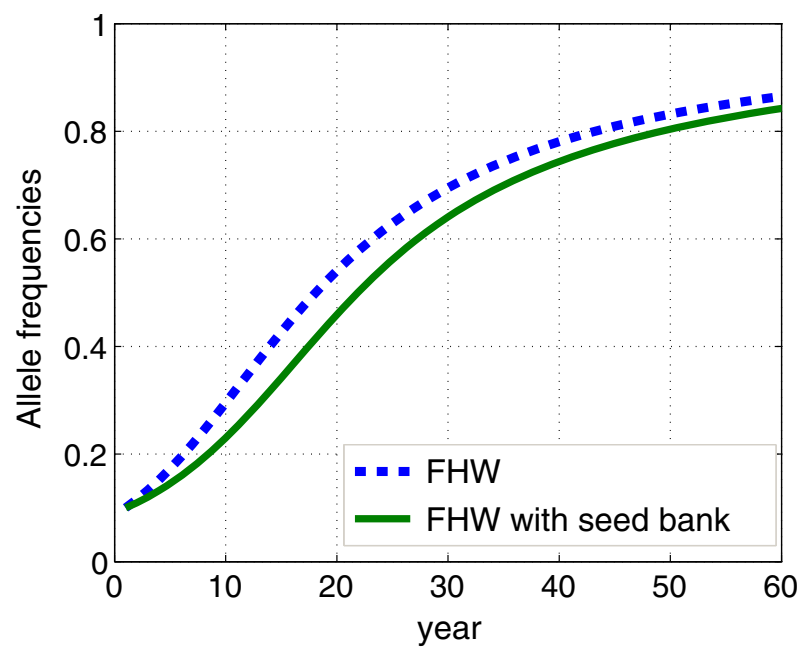

Fig. 3 Allele frequencies (-) FHW model (14) using the seed bank (5) with (8)-(9) and (18) and (--) FHW model (13) for Bidens subalternans with dominant allele, nicosulfuron applied and weak selection $s=0.2$ 
profit of the conventional harvest system with a constant application dose. The seed bank $x^{*}$ and allele frequency $p^{*}$ obtained from the NLP problem were simulated over a 10-year period for an initial seed bank of $500\left(\right.$ seeds $\mathrm{m}^{-2}$ ) and an initial allele frequency of 0.1 . This initial allele frequency indicates that the population resistant is close to be agronomically detectable. The simulation results were obtained using the strategies described in Sect. 4.1.

Figure $4 \mathrm{a}$ shows the seed bank and Fig. $4 \mathrm{~b}$ the resistant allele frequency responses given by the optimum solution herbicide doses. We noticed in Fig. 4a that the seed bank decreased over time and the change in the seed bank was similar for the both herbicides with a NLP control strategy, but we also noticed that the nicosulfuron herbicide is better than the atrazine herbicide to control weeds, this may be explained by the dose-response curves obtained (see Fig. 7).

In Fig. 4b, we noticed that the NLP solution yielded a significantly retard in the allele frequency of the resistant biotypes. The resistant allele frequency increased from $10 \%$ to

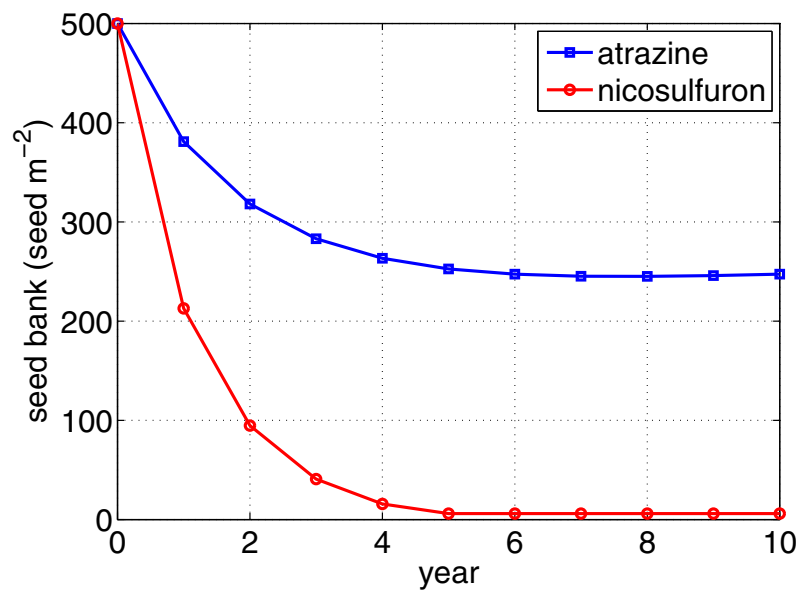

(a)

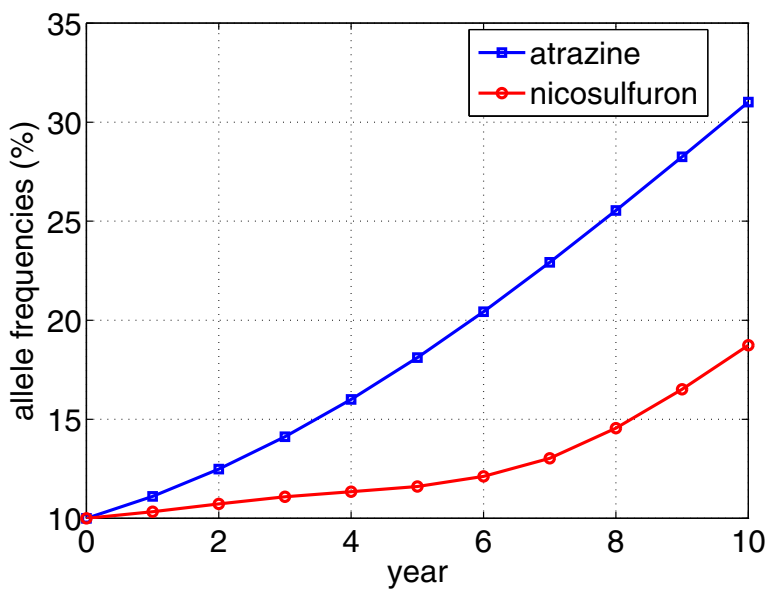

(b)

Fig. 4 Optimal results using the NLP optimal strategy for a 10-year simulation. a Optimal seed bank for nicosulfuron and atrazine. b Optimal resistant allele frequency for nicosulfuron and atrazine 
around $30 \%$ in a 10-year simulation under atrazine herbicide application while the resistant allele frequency of the nicosulfuron herbicide increased from $10 \%$ to around $20 \%$ in the same period of time. Note that, the seed bank control for atrazine herbicide showed a higher level of seeds which reflected also in the level of resistance. Therefore, the adopted optimum strategy was able to reduce the herbicide doses, minimizing the environment damage.

However, the weed control strategy adopted was satisfactory as compared to the conventional management which leads to higher values of resistance. Therefore, the use of new techniques of management that considers optimization strategies can help meeting environmental goals and not only the increase in profit.

Risks of resistance were reduced when a herbicide constant application was replaced by decreasing herbicide doses but maintaining efficacy in the seed bank control. However, not all herbicide application impacted the same selection pressure. Application of a soil residual her-

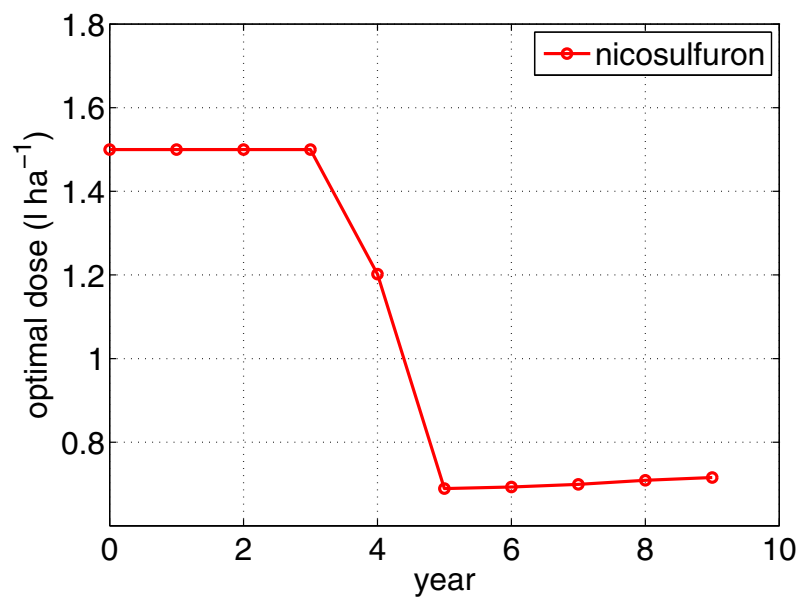

(a)

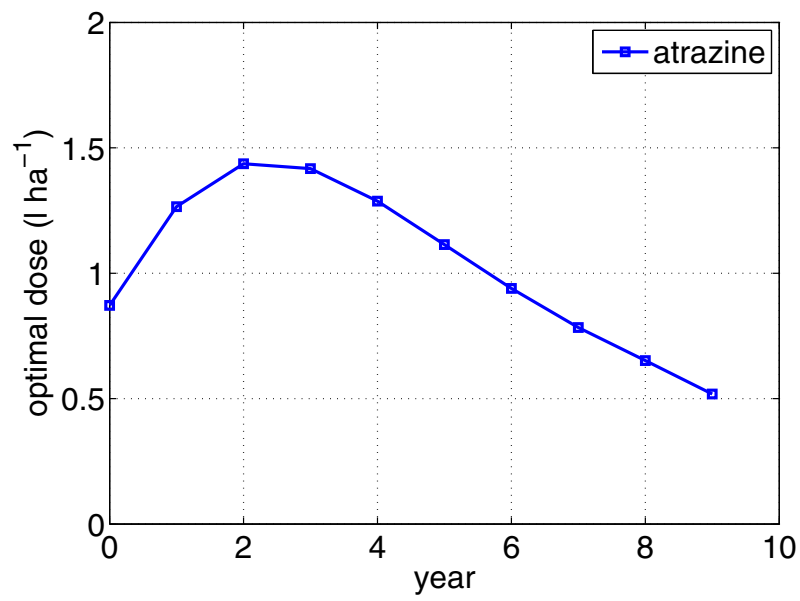

(b)

Fig. 5 Optimal dose $u^{*}$ using NLP strategy for a 10-year simulation. a The nicosulfuron herbicide was applied. b The atrazine herbicide was applied 
bicide at the time of crop sowing season can provide control of Bidens subalternans well into the growing season and significantly reduce the rate and risk of herbicide resistance evolution.

Variation occurred in the time of development of resistance. In general, resistant populations increases more slowly where the germination fraction was low (0.1) (not simulated as the type of weed considered has a high germination fraction). For both types of treatment, the resistance was delayed.

In the simulation scenario, the weed population was controlled for both herbicides applied (see Fig. 4a). Figure 5 illustrates the decreasing in herbicide doses given by the optimal control strategy for both herbicides. Thus, the decrease in herbicide doses is important to reduce the environmental impact caused by excessive use of herbicides.

\subsection{Weed resistance impact on the solution}

Considering the weed resistance to herbicides, we compared the solution of the NLP problem with a conventional strategy. The conventional strategy is based on the application of the

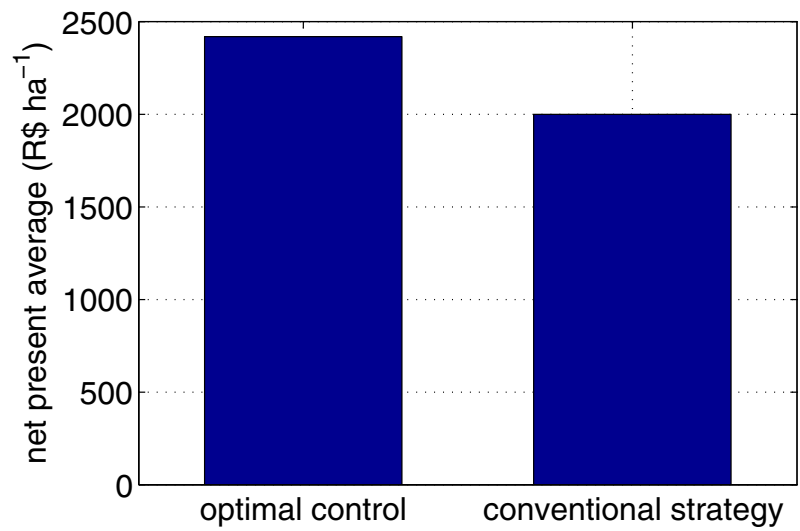

(a)

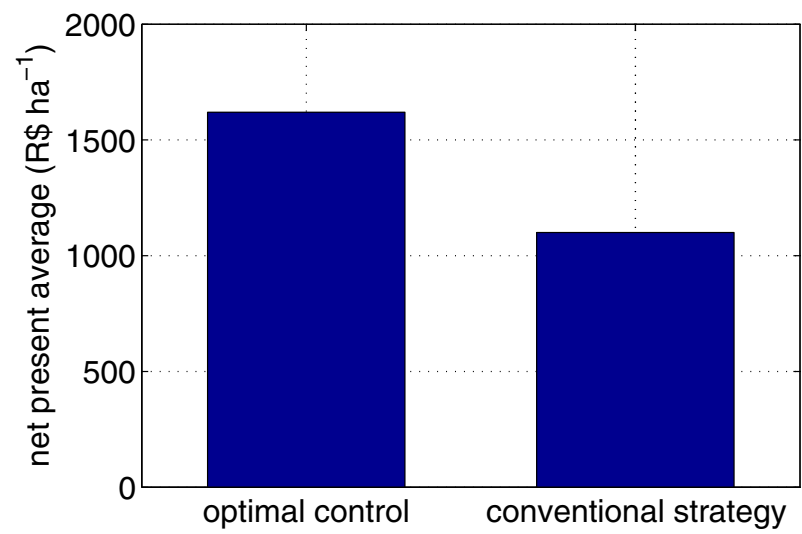

(b)

Fig. 6 Comparison of net values obtained with the optimal control approach for the application of a nicosulfuron and $\mathbf{b}$ atrazine herbicides and the conventional strategy for a 10-year simulation 
maximum dose recommended for the field, following the recommendation indicated on the product label.

The net present values are given in Fig. 6 which indicates that the NLP result is economically superior to the conventional strategy results. In Fig. 6, we noticed that the profit using optimal control strategy for nicosulfuron herbicide was around $20 \%$ superior when compared to the conventional strategy and in case of atrazine herbicide application the profit was around $50 \%$ superior. This fact is due to the price of each unit of product used and the difference showed in weed control by dose-response curves as each herbicide have a different mode of action.

With the goal of maximizing crop returns with minimal environmental effects of herbicides, the formulated optimal control problem to define optimal management strategies for controlling weed population affecting the agricultural production achieved its purpose.

The sensitivity analyses indicated that the model was sensitive to variations in population size and seed bank dynamics. The solution is more sensitive to the initial condition and it is

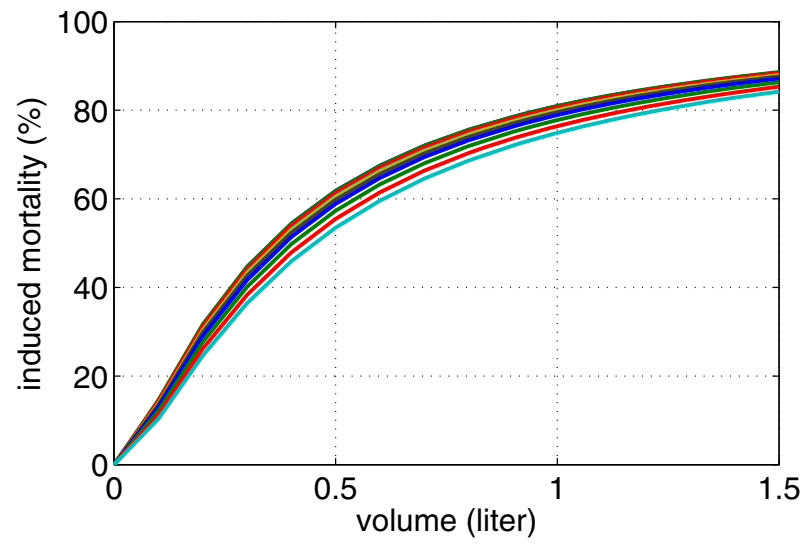

(a)

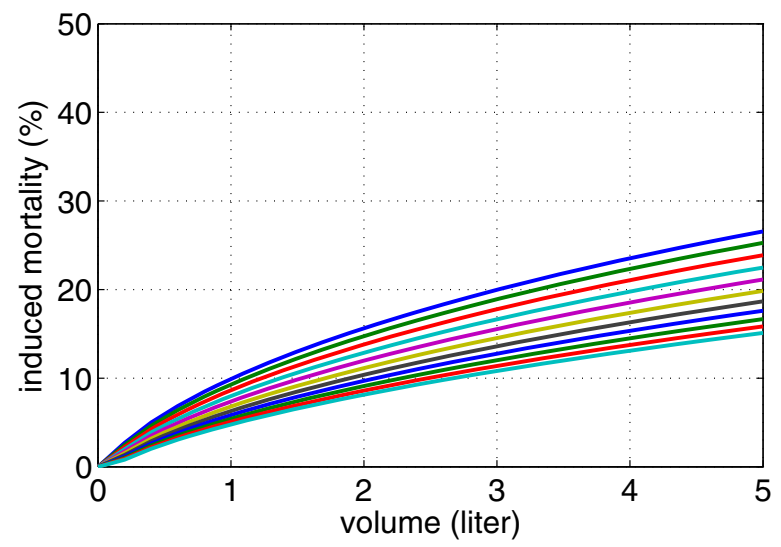

(b)

Fig. 7 Herbicide-induced mortality using the adopted dose-response curve (8) considering the optimal allele frequency $p^{*}$ for $\mathbf{a}$ nicosulfuron and $\mathbf{b}$ atrazine herbicides 
the most difficult parameter to select. The initial population sizes clearly vary from field to field. The annual germination rate, survival rate of new seeds and seed mortality, are clearly influenced by variable climatic and other environmental variables. All these factors contribute to the complexity of the weed population model which makes the study of weed population dynamics the key on agricultural production scenario.

The parameter values of the adopted dose-response model (7) were obtained by curve fitting from experimental data of herbicide-induced mortality (see Table 2). The resulting curves obtained according to (8) for the nicosulfuron and atrazine herbicides are illustrated in Fig. 7.

We noticed in Fig. 7 that the nicosulfuron herbicide is more efficient in weed control than the atrazine herbicide, since the nicosulfuron herbicide showed around $90 \%$ control of weeds while the atrazine herbicide showed around $20 \%$ control. This fact will be reflected in the production cost, the seed bank and the resistance evolution. We observed that the curves obtained using the adopted dose-response function (8) illustrated the change of dose-response curve due to the increase of resistance in the period of time of the

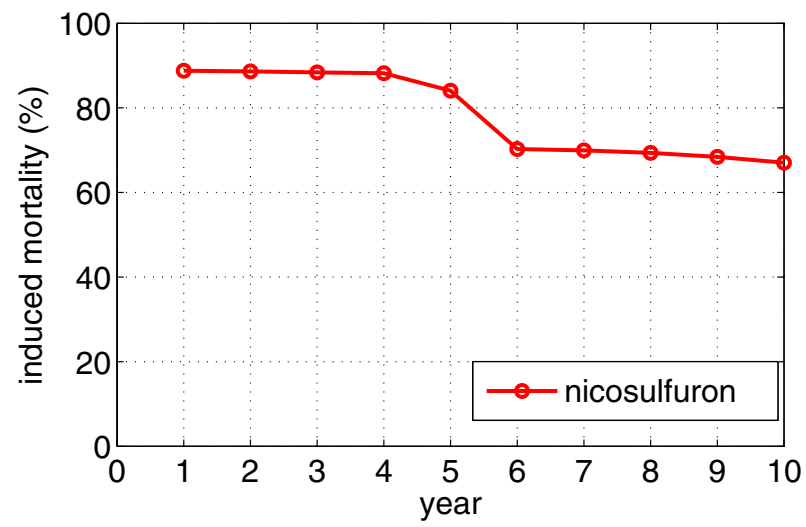

(a)

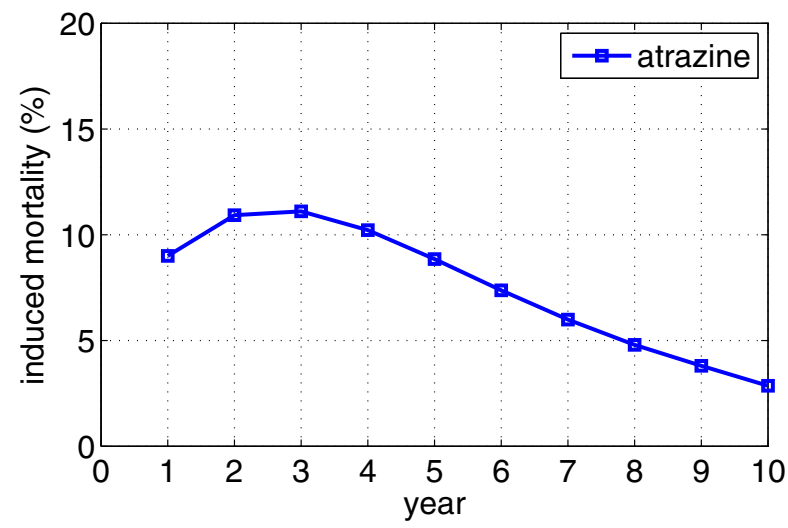

(b)

Fig. 8 Herbicide-induced mortality obtained with NLP optimal strategy, $u^{*}$ and $p^{*}$, for the application of a nicosulfuron and $\mathbf{b}$ atrazine herbicides for a 10-year simulation 
simulation. Therefore, the more resistant plants in the field the less is the efficiency of control applied.

The variation in the mortality rate of plants obtained with the optimal strategy NLP is illustrated in Fig. 8. We noticed that the mortality rate decreases due to the presence of weed resistant. Thus, with the increase of the resistance occurs a reduction in the efficiency of control applied to both herbicides. In this scenario, nicosulfuron was recommended as the herbicide resistance manifests slower and has higher profit while compared to the treatment made with atrazine herbicide.

Moreover, Maxwell et al. (1990) showed that the influence of herbicide efficiency on the evolution of resistance has important management implications. Reducing the control efficiency may delay the resistance evolution due to minimization of selection pressure for resistance. The results presented in this paper confirm these conclusions.

Several proposed strategy to reduce the risk of herbicide resistance evolution use herbicide rotation, sequences and mixture, these had been investigated in Diggle et al. (2003) and Neve et al. (2011). Our modeling analysis has shown that the continuous use of a single herbicide application for long period of time increases the selection of resistant byotype, thus the optimal control of weed can contribute to reduce the herbicide resistance.

\section{Conclusions and discussion}

In this work, we discussed an optimal weed control to support resource management and control in agriculture and a dynamic optimization model which considers the population resistance under selection pressure imposed by the use of herbicide is established. We proposed a single herbicide sequence to control weed infestation by maximizing economic returns and retarding the weed resistance evolution. The results are promising as they indicate that decreased herbicide doses are economically superior to both single herbicide sequences when compared to a conventional practice. In addition, the developed model is useful to explain the evolution of herbicide resistance and to demonstrate that the allele frequency in a population plays an important role in weed management.

The results on optimal control discussed here takes into account important requirements arising in resource management and control in agriculture and will give support to make decision on the herbicide usage in regions where weed resistance was reported by field observations. It is probable that herbicide resistance will only be readily apparent in the field after years of evolution and the practice of herbicide management is essential to retard the resistance evolution in the field. The absence of field management at many locations where the resistance has evolved and lack of detailed knowledge on the precise number of variables involved in the evolution of resistance make model validation problematic as detailed model validation can only be achieved with long-term field experiments and these can be troublesome. Considering these facts, we believe that combining weed dynamic modeling and field observations provides good practice to support resource management. Further work includes the use of rotation of herbicides to improve the control on the seed bank.

Acknowledgements The authors acknowledge the support given by the Conselho Nacional de Desenvolvimento Científico e Tecnológico (CNPq) and the Coordenação de Aperfeiçoamento de Pessoal de Nível Superior (CAPES) under the Programa Nacional de Cooperação Acadêmica (PROCAD). 


\section{References}

Anderson DD, Nissen SJ, Martin AR (1998) Mechanism of primisulfuron resistance in a shattercane (Sorghum bicolor) biotype. Weed Sci 46(1):158-162

Birgin EG, Martínez JM (2002) Large-scale active-set box-constrained optimization method with spectral projected gradients. Comput Optim Appl 23(1):101-125

Birgin EG, Martínez JM, Raydan M (2000) Nonmonotone spectral projected gradient methods on convex sets. SIAM J Optim 10(4):1196-1211

Britton NF (2003) Essential mathematical biology. Springer Undergraduate Mathematics Series, London, UK

Byrd RB, Lu P, Nocedal J, Zhu C (1995) A limited memory algorithm for bound constrained optimization. SIAM J Sci Comput 16(5):1190-1208

Carvalho FT, Moretti TB, Souza PA (2010) Eficácia e seletividade de associações de herbicidas utilizados em pós-emergência na cultura do milho. Rev Bras Herbic 9(1):35-41

Christensen S, Streibig JC, Haas H (1990) Interaction between herbicide activity and weed suppression by spring barley varieties. In: Seventh European Weed Research Society Symposium, Helsinki, 367-374

Christiaans T, Eichner T, Pething R (2007) Optimal pest control in agriculture. J Econ Dyn Control 31(12):3965-3985

Christoffoleti PJ (2002) Curvas de dose-resposta de biótipos resistente e suscetível da Bidens pilosa L. aos herbicidas inibidores da ALS. Sci Agric 59(3):513-519

Christoffoleti PJ (2008) Aspectos de resistêcia de plantas daninhas a herbicidas, 3rd edn. Associação Brasileira de Ação à Resistência de Plantas Daninhas, Piracicaba, SP

Cousens R (1985) A simple model relating yield loss to weed density. Ann Appl Biol 107(2):239-252

Dan HA, Procópio ALL, Dan SO, Finotti TR, Assis RL (2010) Seletividade do atrazine à cultura do milheto Pennisetum glaucum, Planta Daninha, 28 no. spe, 1117-1124

Diggle AJ, Neve PB, Smith FP (2003) Herbicides used in combination can reduce the probability of herbicide resistance in finite weed populations. Weed Res 43(5):371-382

Gazziero DLP, Santos AMB, Voll E, Adegas FS (2008) Resistência de picão-preto (Bidens subalternans) ao herbicida atrazine, in: Congresso Brasileiro da Ciência das Plantas Daninhas e Congresso de la Associacón Latinoamericana de Malezas, Ouro Preto, 7

Gressel J (2009) Evolving understanding of the evolution of herbicide resistance. Pest Manag Sci 65(11):11641173

Gressel J, Segel LA (1978) The paucity of plants evolving genetic resistance to herbicides: possible reasons and implications. J Theor Biol 75(3):349-371

Hager WW (2009) Source code for ASA-CG version 1.3, Available at: http://www.math.ufl.edu/ hager/ papers/Software

Hager WW, Zhang H (2006) A new active set algorithm for box constrained optimization. J Optim 17(2):526557

Heap I (2011) The international survey of herbicide resistant weeds, Available at: http://www.weedscience. com

IMEA (2014) Custo de produ ção de milho-Safra 2013/14, Available at: http://www.imea.com.br/upload/ publicacoes/arquivos/R410-2013-01-CPMilho.pdf

Jones R, Cacho OJ (2000) A dynamic optimization model of weed control. 44th Annual Conference of the Australian Agricultural and Resource Economics. Australia, Sydney, pp 1-17

Jones R, Cacho OJ, Sinden J (2006) The importance of seasonal variability and tactical responses to risk on estimating the economic benefits of integrated weed management. Agric Econ 35(3):245-256

Karam D (2011) Manejo de plantas daninhas resistentes na cultura do milho. Plantio Direto 20(124):40-46

Karam D, Lara JFR, Magalhães PC, Filho IAP, Cruz MB (2004) Seletividade de carfentrazone-ethyl aos milhos doce e normal. Rev Bras Milho e Sorgo 3(1):62-68

Kennedy JOS (1986) Dynamic programming: applications to agriculture and natural resources. Elsevier, New York, NY

Kotani K, Kakinaka M, Matsuda H (2009) Dynamic economic analysis on invasive species management: Some policy implications of catchability. Math Biosci 220(1):1-14

Kotani K, Kakinaka M, Matsuda H (2011) Optimal invasive species management under multiple uncertainties. Math Biosci 233(1):32-46

Lin CJ, Moré JJ (1999) Newton's method for large bound-constrained optimization problems. SIAM J Optim 9(4):1100-1127

Maxwell BD, Roush ML, Radosevich SR (1990) Predicting the evolution and dynamics of herbicide resistance in weed populations. Weed Technol 4(1):2-13 
Medd R, Nicol HI, Cook A (1995) Seed kill and its role in weed management system: A case study of seed production, seed banks and population growth of avena species (wild oats). Ninth European Weed Research Society Symposium, Budapest 2:627-632

Moss S (2010) Detecting herbicide resistance, Available at: http://www.hracglobal.com/Publications/ DetectingHerbicideResistance/tabid/229/ Default.aspx

Neve P, Norsworthy JK, Smith KL, Zelaya IA (2011) Modelling evolution and management of glyphosate resistance in Amaranthus palmeri. Weed Res 51(1):99-112

Oliveira AT, Santos JB, Camelo GM, Botelho RG, Lázri TM (2009) Efeito da interação do nicosulfuron e Chlorpyrifos sobre o banco de sementes e os atributos microbianos do solo. Rev Bras Ciência do Solo 33(3):563-570

Pandey S, Medd R (1990) Integration of seed and plant kill tactics for control of wild oats: An economic evaluation. Agric Syst 34(1):65-76

Powles SB, Preston C (2011) Herbicide cross resistance and multiple resistance in plants, Available at: http://www.hracglobal.com/ Publications/ HerbicideCrossResistanceandMultipleResistance / tabid/224/Default.aspx

Powles SB, Shaner DL (2001) Herbicide resistance and world grains. CRC Press, London, UK

Rafikov M, Balthazar JM (2005) Optimal pest control problem in population dynamics. Comput Appl Math 24(1):65-81

Ralebitso TK, Senior E, Verseveld HWV (2002) Microbial aspects of atrazine degradation in natural environments. Biodegradation 13(1):11-19

Seefeldt SS, Jensen JE, Fuerst EP (1995) Log-logistic analysis of herbicide dose-response relationships. Weed Technol 9(1):218-227

Streibig JC, Kudsk P (1993) Herbicide bioassays. CRC Press, Boca Raton, FL

Tind T, Mathiesen TJ, Jensen JE, Ritz C, Streibig JC (2009) Using a selectivity index to evaluate logarithmic spraying in grass seed crops. Pest Manag Sci 65(11):1257-1262

Tranel PJ, Wright TR (2002) Resistance of weeds to ALS-inhibiting herbicides: what have we learned? Weed Sci 50(6):700-712 